EPRA International Journal of Economic and Business Review-Peer Reviewed Journal Volume - 9, Issue - 11, November 2021 | e-ISSN: 2347 - 9671| p- ISSN: 2349 - 0187

\title{
CONCEPTUAL FRAMEWORK FOR VALUING IT WITHIN A BUSINESS SYSTEM
}

\author{
Dr.G.Naresh Reddy ${ }^{1}$, Asiya Jabeen ${ }^{2}$ \\ ${ }^{1}$ Associate Professor, Department of Commerce, UCC\&BM, Osmania University Hyderabad \\ ${ }^{2}$ Assistant Professor, Department of Commerce, \\ Indira Priyadarshini Govt Degree College for Women, Nampally, Hyderabad
}

\begin{abstract}
DOI No: 10.36713/epra8920

Article DOI: https://doi.org/10.36713/epra8920

Due to the complexity of IT impacts and multiple interpretations of value, determining the IT value can be difficult. This paper introduces a conceptual framework for evaluating IT value within a single firm despite its complexity. Our research combines design science with an examination of five real-world scenarios. Using the conceptual framework, we may look at value from three different perspectives: 1) from the standpoint of diverse stakeholders, 2) from the perspective of valuing logics, and 3) from the perspective of assessment views. It's important to consider all of these viewpoints because they help to build the foundation for understanding how specific value information might fulfill the demands of IT-related decision making and how to evaluate and communicate it.
\end{abstract}

KEYWORDS: IT, conceptual framework, multifaceted, company

\section{INTRODUCTION}

More and more development and investment plans incorporate specific IT elements, either in an enabling or supporting function, and as a result, information technology (IT) has become a frequent topic in company decision-making. Decision-making is supported by IT evaluation, which establishes the value or contribution produced by a certain IT investment ${ }^{1-3}$. When it comes to IT evaluation, the goal is to figure out how investments will be affected by IT, and IT value helps to explain those impacts in a way that aids in decision-making. However, determining the value of IT is a difficult issue ${ }^{4,5}$. This task is divided into two parts because of how intertwined they are: First, describing and comprehending the influence of IT on a business system; second, interpreting and appreciating the value in multiple ways. Our study topic is formed by the junction of these two aspects - evaluating the goodness of IT impacts, for example ${ }^{7}$. From the standpoint of IT impacts, contemporary literature recognizes challenges such multilevel goals and broad IT impacts, intangible and delayed effects, various complimentary elements determining the impacts, and indirect attributability of economic paybacks when approaching this subject ${ }^{8-10}$. The theoretical underpinning is dispersed and difficult to use for practical evaluation solutions, despite substantial research on evaluation principles and 
conceptualisations. Over the past two centuries, philosophers, scholars, and practitioners have been attracted by the concept of value. However, misunderstandings and overloaded meanings have plagued the field ever since. Defining value can be difficult because it can mean many different things depending on how it is used, such as a synonym for "utility" or "benefit towards goals," or "business value of IT," which is a catchall term for the contribution of IT to company performance ${ }^{11,12}$. On an individual level of analysis, in addition to utilitarian viewpoints, phenomenal and hedonic value foundations are also utilized. Organizational productivity and performance can be examined on many different levels, including whether and how much IT has an impact on them. Traditional financial measurements alone are troublesome for valuing current information technology, according to our research on the level of an individual company evaluating the worth of a specific IT system. In order to evaluate IT impacts, it appears that integrative and multilevel evaluation is needed, but the appropriate holistic value conceptualization lacks ${ }^{13}$. By answering the research question "How to conceptualise IT value for evaluation purposes within a business system?," the objective of this study is to clarify the complicated phenomenon of IT value evaluation. It's a socio-technical system that includes the company's mission, goals, structure, operations, people, and technology. A specific IT system and its use as part of the business system are covered by IT as a target for evaluation and investment decisions ${ }^{14}$. With this conceptual framework, we want to better grasp the value of information technology. The Conceptual Framework should make it easier for stakeholders to understand and assess value in distinct but complementary ways during the overall evaluation process. Those who use the results of the evaluation and those who provide value perceptions or other information for the evaluation are all stakeholders. Understanding the IT value idea together should assist to focus evaluation operations, identify evaluation techniques, and operationalise value constructs as practicable metrics. Conceptual Framework applies widely recognized principles of multilevel analysis, a balanced view of the performance of business systems, and an IT evaluation lifecycle view ${ }^{15}$. The multilevel and multiperspective system inquiries are integrated using a systemic method with systems thinking as the underlying concept. As a result, the value idea is used from the perspectives of value creation and value determination, guaranteeing that the evaluation covers both the processes that affect value and the results of those value creating mechanisms. A cooperative industrial-research initiative has provided empirical roots for Conceptual Framework. To develop a
Systemic Evaluation Approach, the team used a design science approach in five different companies. During the development and testing of the solution, it became clear that the notion of value was constantly shifting ${ }^{16-}$ 19. All five evaluations were motivated by the same goal: to determine the worth of a certain IT system and then make decisions based on that value for the system's future. Despite this, the instances had varying interpretations of value and differing requirements for the substance and style of usable value information, despite the common basis. This observation from the field, together with the sporadic mentions of methodological foundations in evaluation literature, prompted the development of the Conceptual Framework described in this paper.

\section{METHODOLOGY}

This paper offers a conceptual framework as its primary contribution. Conceptual frameworks play a crucial role in design science research since they serve as a foundation for the development of theories as well as answers to practical challenges. Conceptual framework ${ }^{20}$, is used "to frame a research subject, characterize phenomena, and assess their structure". In a certain problem situation, conceptual framework can be a collection of complex constructs used to define and explain the phenomenon and related produced artifacts.

\section{DESIGN SCIENCE AS A RESEARCH APPROACH}

We conduct our study using a design science methodology focused on real-world problems. Both construction and improvement challenges in a specific context and the generalisation of design knowledge about solutions in context are the two main goals of design science as a whole. The contributions of design science include objects such as models, constructs, and procedures. New innovations or a better state of affairs are instantiated (i.e. realized) in the issue environment as artifacts. A scientific viewpoint sees artifacts as both representing and being the source of generalized knowledge contributions such as identifying essences and relationships in the research territory (i.e, conceptual knowledge), describing and explaining things (i.e, descriptive knowledge), or prescribing methods for achieving objectives (prescriptive knowledge). Design science differs from other problem-solving activities in that it makes a significant contribution to the body of knowledge $\mathrm{e}^{21,22}$.

An artifact's design and utility are evaluated in a build-and-evaluate loop, which is central to design science. The build activity generates and evaluates knowledge contribution as well. 


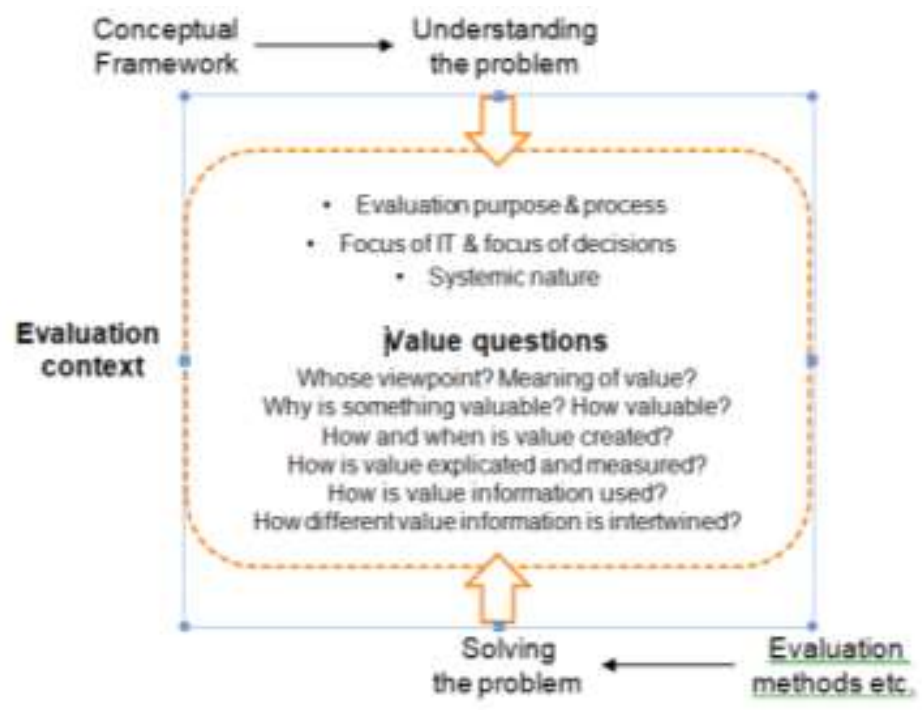

Fig. 1. Evaluation context and positioning Conceptual Framework in a continuum of understanding the problem of IT evaluation and utilising this understanding in evaluation solutions ${ }^{23}$ Iterations of design and investigation combine construction-oriented problem solving with a search for generalizable information. Here, we pay particular attention to the conceptual knowledge contribution and present a comprehensive understanding for the phenomenon of IT value evaluation. Conceptual Framework is the name we've given to our body of knowledge. The design science project's problemsolving iterations focused on creating and testing a solution artifact. Approach to Systemic Evaluation for evaluating the value of IT. This paper only treats Conceptual Framework as a source of case experiences for justifying and evaluating the decisions made with Conceptual Framework as a part of the Systemic Evaluation Approach1. This paper's focus on Systemic Evaluation Approach's prescriptive knowledge reporting frees up space and quality for Conceptual Framework's presentation and reasoning.

\section{CASE DESCRIPTIONS AND DATA ANALYSIS}

'Host Company' served as an IT service provider for all five of the organizations in Table 1. Since 2012, the Aalto University research group has worked with Host Company on service development, and Case A officially began in the spring of 2013. In the spring of 2015, researchers finished compiling data on Case E. Case A was used to construct the first implementation of the Systemic Evaluation Approach, along with early versions of the Conceptual Framework, which were then tested and refined in subsequent instances.

A specific IT system was being evaluated in each scenario - either an existing one or a potential one
- for its value and value generation mechanisms. Overall, the workflow was as follows: familiarize yourself with the assessment topic, establish an evaluation team, specify the evaluation objectives, model value creation, and design metrics to explain value. System dynamics modeling and simulation was used in conjunction with workshops and interviews as part of the research process ${ }^{24,25}$.

The action research strategy was used in the first three Cases A through C. Systemic Evaluation Approach was developed and used by Case A's first author as a leadership role, whereas in Cases B and C, the first author helped participants from Host company in applying and further developing article. For the rest of the cases, a case study approach was used, in which the researcher was an observer and commentator in evaluation workshops and other activities. After each case was finished, members of the evaluation teams were interviewed.

Workshops and interviews were used to gather data, as well as process descriptions and meeting memoranda. Atlas.ti software combined, coded, and analyzed written data with that from transcribed workshops and meetings. Individual, process, and organization goals were examined, as well as how information technology (IT) impacted them. These were the main focus points for data analysis. Insights into several levels of IT value analysis were originally supplied by roles and responsibilities. Individual goals could be linked to the organization's overarching objectives with the use of insights about the processes and their goals. Explicit models of earnings reasoning per instance were developed to better comprehend the organization's objectives ${ }^{26,27}$. As an interim result, all scenarios created a cause-and-effect value creation diagram. These graphic models included the evaluation team's shared understanding of how several objectives, 
IT impacts and multiple influencing elements were connected together (enabling, blocking or complementing). Using these models, multiple value logics, abstraction levels, and evaluation views for presenting the results of valuing efforts might be identified.

The early versions of Conceptual Framework were derived from data analysis and literature reviews for assessing value and the effectiveness of information technology. Two intermediary analytic tools were employed for the final version, which is described in this work. Using the Conceptual Framework as a framework, Appendices A and B analyze and map out the situations. Appendix screenshots are used to demonstrate Conceptual Framework's usefulness (Section 5). To create the maps in Appendices A and B, the criteria in Appendix C must be met.

\section{METHODS FOR ASSESSING CONCEPTUAL FRAMEWORK}

We evaluate the usefulness and relevance of the conceptual framework offered (Table 3) using three sets of criteria:

Evaluation of the design's objectives

Determining the validity of a construct

\section{ANALYZING NEW INFORMATION IN LIGHT OF THE EXISTING BODY OF KNOWLEDGE}

The design objectives emphasize the role that Conceptual Framework should have in identifying the evaluation environment. A conceptual framework's main assessment criterion is its construct validity, which can be defined as "the amount to which an application of a construct to phenomena is justifiable." We relate the Conceptual Framework constructs to real-world instances retroactively using artifact development scenarios (Appendixes A and B). We use Wieringa's standards to determine the degree of construct validity (2014). All study utilizes a third method of evaluation. You should contribute fresh information and make the existing knowledge base more engaging in exchange for your effort (Hevner et al., 2004). There is a novel method to valuing IT in a business system, as discussed in the literature section. As mentioned in Appendices A and B, interest level and relevance of Conceptual Framework for research cases are both evaluated.

Table 2 : The cases and their IT systems under evaluation

\begin{tabular}{lll}
\hline Case & Domain & Target IT system \\
\hline A & Gambling \& gaming provider & $\begin{array}{l}\text { Existing game management system } \\
\text { (GMS) }\end{array}$ \\
B & $\begin{array}{l}\text { Network service \& infrastructure } \\
\text { provider }\end{array}$ & $\begin{array}{l}\text { Existing billing \& ticketing system } \\
\text { (ERP) }\end{array}$ \\
C & Grocery retailing & $\begin{array}{l}\text { Existing travel expense management } \\
\text { system }\end{array}$ \\
D & Computer \& communications & Future cloud-based product development \\
& security & \& testing environment \\
\hline
\end{tabular}

\section{CONCEPTUAL FRAMEWORK}

An IT value evaluation includes two steps: first, identify the effects of IT and then assess their goodness (i.e. value) in comparison to each other. In every evaluation, context is established by the focus of IT being evaluated and by the focus of decisions determining what required value information is.

Three aspects are covered by the conceptual framework (Fig. 2): In order to investigate the value in a business system, one must look at three levels of analysis: the levels of analysis used to look at the value itself, the valuing logics used to define the valuing mechanisms, and the assessment views for systemic and operationalization elements. With the use of these three viewpoints, the jumble of value creation, determination, and presentation concepts may be clarified and interconnected ${ }^{28}$.

\section{Analysis levels}

The concept of many levels of analysis is crucial for figuring out how different parts of the organization evaluate value. Diverse perspectives on what is regarded useful serve as a springboard for gaining a comprehensive understanding of the business system. For understanding complexity, Gharajedaghi (2011, p. 93) recommends using the iterative process of holistic thinking. Using the cyclic process, different levels of an organization can learn about the function, structure, and process of a system. Taking a look at the answers to these questions helps reveal the objectives of a particular subsystem as well as the structures and 
processes that help achieve those objectives. Information technology (IT) effects can be measured against goals or at a method level, such as how well IT supports or fits the methods of achieving goals. When seen as a whole, a company's aims and means constitute a cause-and-effect chain. Multiple layers of analysis are aimed at these multilevel cause-and-effect systems, which serve as the foundation for a systemic knowledge.

A socio-technical business system analysis of a particular organization is the focus of our examination. As a starting point for analyzing IT impacts, we advise looking at three levels: organizational, process, and user. While maintaining a Conceptual Framework basic enough for broad applicability, this level of precision allows for the early detection of anal- ysis touchpoints. Using the touchpoints, you should be able to determine the overall business system goals (organizational level analysis), system structure and functions (process level

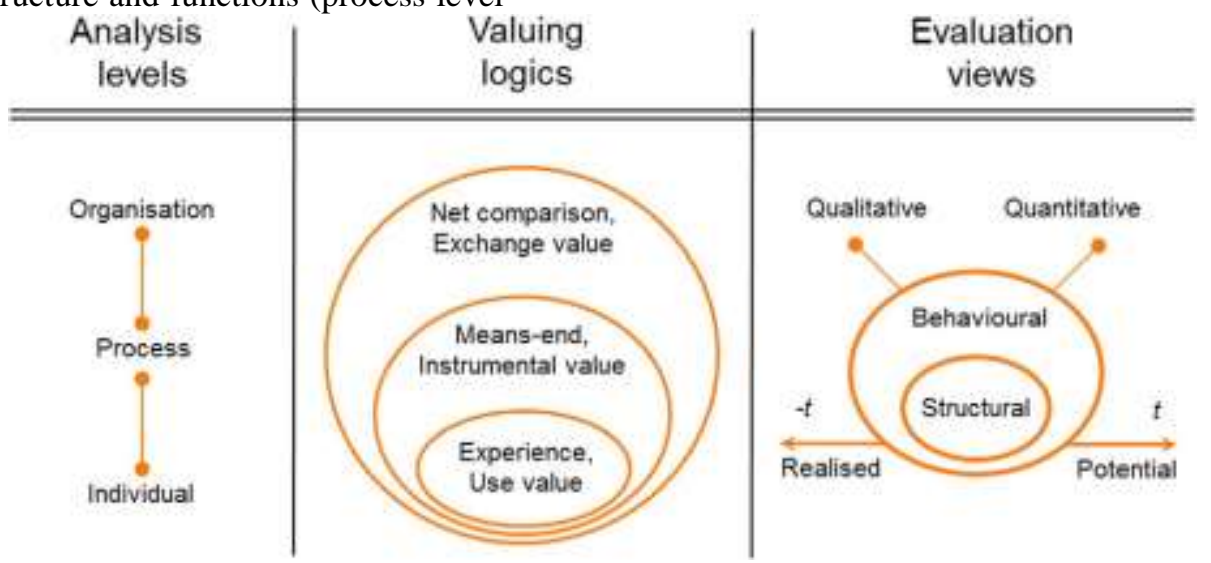

Fig. 1. Conceptual Framework with three perspectives for valuing IT.

The first-order effects of IT investments are felt and the organization advantages are realized at the process level, according to some experts. Information technology (IT) helps businesses by improving the efficiency of their particular processes and/or interprocess linkages. Some business processes include inbound logistics, production, sales and distribution as well as providing excellent customer service. The efficiency, flexibility, and satisfaction of these processes are all operationalized through various metrics ${ }^{30}$.

Individual users are often the first point of contact between an IT system and the broader business system, even if the process level is where most IT impact analysis takes place. IT processes and distributes information that users submit. Users then exploit this processed and dispersed information. Individual users serve as a vital link between the negative effects of IT and the positive effects it has on an organization as a whole. Intentions to use IT are analysis), and users' subjective impressions of IT impacts (individual level analysis).

The total influence of IT on the company's or business unit's performance is the focus of organizational level analysis. For example, profitability, ROI, or Net Present Value (NPV)-type financial measurements are typical operationalizations of this level of research. Analysis at the organizational level is driven by operational and strategic business objectives, which are then propagated downward to guide the objectives at the process and individual levels. These organizational goals should also serve as a proxy for the business system's external environment (such as the markets it serves with customers, partners, and competitors). We purposely limit the scope of the evaluation by eliminating markets outside the bounds of the business system and by assuming that the organization's aims are in line with the current environment $^{29}$. 
the result of a person's intentional decision-making process. This logic combines the goal of exchange value, which can be described as "goodness for trade with anything," with the net value approach's processes. As defined as the trade-off between positive consequences (benefits) or desired outcomes and negative consequences (sacrifice) or costs, the net value method always has two value-driving factors ${ }^{31}$.

Many financial value statements at the organizational level are the outcome of net comparison logic, however this is not a requirement for using net comparison logic in your research. The projected monetary worth of the benefits minus the estimated costs, for example, can lead to an overall valuation for IT investment at an organizational level of analysis using net comparison. If the investment is accepted, the information gleaned from the process is used to make the final decision. We can compare the IT-enhanced process productivity changes with IT acquisition and maintenance expenses in an example at the process level. This data is also used to determine a budget for process and IT alignment improvements. For example, an employee can weigh the benefits of IT against the additional labor it necessitates for her task performance and then decide whether to stick with an old workaround or put in more time learning how to use IT effectively. In the logic of means-ends, the methods of value generation are emphasized rather than the value itself. In this paper, value creation is compared to a web of cause-and-effect relationships. The cause-and-effect chain starts with first-order IT investments made at the individual level and extends via processes to the overall performance of the organization ${ }^{32}$.

We use a means-to-end chain as a fundamental building component to better understand how systems generate value. The hierarchies of goal structures - the sequences of subordinate and superordinate objectives - are formed by means-end chains. Different stakeholders in a business system can be linked together by using these hierarchies. As value creation mechanisms, the linked goal structures (constructed from means-end chains) can be used to track and link IT impacts with consequences. IT plays an essential role in value creation mechanisms; value reflects IT's ability to enable or facilitate the achievement of desired goals.

Net comparison and means-end valuing logics differ in that their operationalisation into distinct objectives and metrics through summative and formative evaluation methodologies can help elucidate the discrepancies. Summative evaluation, according to Hamilton and Chervany (1981), establishes if the system has met its goals. A formative evaluation, on the other hand, looks at how well the development process or methods are working toward achieving the desired results. Using a net comparison approach for summative assessment is similar to using a means-end evaluation approach. Efficiency-oriented goals like better inventory management and more customer satisfaction are examples of summative evaluations operationalized. Formative evaluation emphasizes efficiency-oriented goals such resource consumption, manufacturing capability, and resource investment ${ }^{34,35}$.

Experience logic is concerned with how people perceive the influence of IT in the actual world. To define value, we must look at it as a dynamic practice of generating value through the movement of acts, practices, and processes within a created dynamic framework". Value is something that is felt, not something that is compared or evaluated based on advantages and disadvantages ${ }^{37}$. Other value logics often take over and form on the memories of the experience before the raw experience is ever seen. By consuming more time and space in between the valuecreating moment of the experience and the moment of evaluating value from it, alternative interpretations, biases, measurement mistakes and other "noise" variables are more likely to occur ${ }^{38}$.

Because of this, it's important to recognize experiences that have their own logic of value. Analyzing the value at the individual level allows us to use that value as a starting point for additional valuation logics, such as perceptual or independently observable metrics. So the value of experience reflects the will of persons to use IT, which is a crucial complimentary aspect for IT's ability to accomplish the desired investment goals.

\section{Evaluation Views}

This section of the Conceptual Framework presents viewpoints that are strongly related for explaining the systemic nature of value, the value lifecycle over time, and the explicitness of measuring and analyzing value explicitly. When creating evaluation models and analyzing and extracting results from the evaluation models, evaluation views are used to model real-world challenges (interesting from the perspectives of value production and determination).

The foundation for elaborating value is a structural view of the business system, and all other evaluation viewpoints build on this understanding. When looking at a business system holistically ${ }^{39}$, a structural viewpoint allows for a better understanding of the value-creating and -affecting parts as well as their relationships. Different functions, processes, inputs and outputs of functions/processes, IT impacts on these inputs and outputs, and other complimentary components connected to IT impacts can all be represented by these elements. The same is true with metrics, especially if they have the ability to influence or govern other elements or connections. Different system stakeholders' objectives also fall under the 
category of control-oriented aspects. A few examples of structural perspective value statements are: This is valuable because it allows us to, or These concerns have an impact on our success ${ }^{40}$.

System behavior can be either static or dynamic depending on how value elements behave. Static value elements' states change independently of the system's history, so their values remain constant across time. A steady stream of processed transactions (a gain) and fixed software license charges (a sacrifice) are two examples of static value-creating/affecting factors. When a system (or an element) changes its state over time, its dynamic value changes as well. The feedback linkages and accumulative element types already indicate dynamic behavior on a structural system view (i.e. stocks or buffers). Delays introduced by feedbacks and buffers can have the opposite impact of what you expect. A business system's overall value production behavior is, by definition, dynamic ${ }^{41,42}$.

Between potential and realized value, time and system behavior function as intermediary elements. Lifetime uum of the value In contrast to realised value, which is something that has already occurred and already exists, potential value is something that can be expected in the future. When there's uncertainty about how the system will behave, there's a danger that value won't be realized. Potential advantages are referred to as benefit assertions by Wiseman (1992), who emphasizes the danger of value realization. It's critical to discover the moderating or complimentary aspects that influence value realisation when benefit statements and realized benefits are separated (i.e., cost or sacrifice statements). A temporal continuum is created when potential and realized value views are combined. This continuum can encompass the entire IT investment lifecycle, from decision-making preparation to ensuring and increasing the paybacks of an IT system in operation $^{43}$.

In order to create and determine value, structural and behavioral understanding is operationalized through qualitative and/or quantitative insights into explicit knowledge Depending on the objectives, operationalization can focus on value composing parts (such as benefits and sacrifices) or value generating methods (such as causal links). It can also focus on the outputs of these mechanisms (such as the overall net value) (e.g. enablers, blockers). You can use qualitative-quantitative perspectives on various abstraction levels of value and value evaluation, such as measurement/data types or systemic analysis types, to apply qualitative-quantitative viewpoints.

In the "real world," measurements give us information about the problems we are trying to solve. These topics include the effects of information technology (IT) as well as other value-influencing variables that feed value assessment. Intangible, soft, or subjectively perceived impacts and elements such as improved reporting or improved operational flexibility can be problematic. Some of the problems can be described as concrete, difficult to ignore and measurable on their own, such as the reduction in the number of production failures. Problems become variables with a measurement scale when they are measured. Ordinal, interval, and ratio scales allow for quantitative measurements while nominal scales do not have any numerical or quantitative qualities. As an output, quantitative measurements provide quantitative data; for example, they enable the discussion of variable quantities. Other inquiry methods, like as interviews, can produce qualitative data on the topic under evaluation, such as IT benefit categorizations or stories about ideas and sentiments about IT impacts ${ }^{44}$.

If qualitative or quantitative data/measurements are used in the systemic analysis, the results will be mixed. In other words, the results of the research provide answers to case-specific questions about the value of IT. We use qualitative-quantitative analysis views from system dynamics to characterize the entire systemic value understanding. When it comes to the overall scope of systemic understanding, qualitative and quantitative perspectives are used ${ }^{45}$. The initial insights into system architecture and interactions come from qualitative understanding. Having access to this kind of information can help you learn about the many perspectives of stakeholders and create a shared understanding of the system as a whole. Using numbers and equations to express system behavior and state allows us to see how system variables and constants are related numerically and mathematically. This type of information covers numerical facts or estimates, either absolute or relative, potential or realized, as an evaluation outcome. Quantitative views link instance data with equations and state information to identify "placeholders" for the issues to be observed (i.e. metrics to be measured) from a value operationalization perspective. Qualitative views, on the other hand, identify the placeholders ${ }^{46}$.

\section{Demonstrating Conceptual Framework}

In the next section, we show how the Conceptual Framework's constructs aid in comprehending IT value evalu- ation in our case studies. Case A serves as a working example of the Conceptual Framework, and examples from other instances are used to round out the presentation. Game Management System (GMS) was used in Case A by a gaming operator (GMS). For managing the lifetime of numerous gaming goods, GMS was utilized, from content preparation through public opening and closing to publishing game results. GMS was used to manage these lifecycles. 


\section{Samples for analysis levels}

Analysis levels require system stakeholders and their goals must be identified at the start of the review process. The objectives serve as a starting point for determining the relative importance of different types of IT impacts. A total of three tiers of information was acquired in Case A. Participants on the evaluation team represented a variety of groups with ties to GMS. Different GMS impacts piqued the interest of stakeholders.

Owners of gaming products spoke for the organizational level. It was gaming money that they were most concerned with. Gaming operators and game designers were on hand to represent the process level. They were concerned with the speed, quality, and appeal of gaming content rather than gameplay itself $9^{47,48}$.

Stakeholders at the organizational and process levels were represented by GMS users at the individual level as well. Routine task efficiency was a priority, as was human error minimization and the time saved for developing game content. Multilevel analysis helped stakeholders understand one another better and gave business and technology professionals a "common language." According to the Case A team, previous "enterprise architecture" type documentation had failed to foster a sense of shared purpose among the project's stakeholders. The only analysis level consistently present was the process level ${ }^{50}$. The direct organization and individual level analysis were absent, for example, in Case C (ERP). Merchandising and procure-to-pay business use cases employed IT and business architects as proxy for organizational success. However, as the evaluation phase progressed, the significance of connecting the analysis with marketing and sales objectives grew.

There was no clear individual level analysis in examples $\mathrm{C}$ and $\mathrm{E}$ (cloud-based development environment). There were several factors that contributed to this, but one was the sheer size of IT systems that were being evaluated in relation to a business system. This meant that much of the analysis time was spent on process or organizational levels.

\section{Samples for valuing logics}

Identification of various valuing logics assisted in composing various value conceptualizations of stakeholders into a meaningful whole instead of competing. The scenarios illustrated how value might be goodness in experiences, goodness of means in reaching goals, or relative comparison with resources or sacrifices required to achieve goodness.. GMS impact on gaming turnover was calculated in Case A using net comparison logic: turnover impact $=($ gaming turnover with GMS gaming turnover without GMS) GMS costs. Gaming turnover was demonstrated to be enabled by GMS using a means-end logic approach. It was found that several impact chains (also known as value channels) flowed from the GMS use to gaming turnover (e.g., through labor efficiency, content and process quality in gaming, gaming volume, and brand image in gaming). The use of experience logic demonstrated how users saw GMS automation as freeing up their time for more strategic preparation of gaming content instead of mundane repetitive duties $^{51,52}$.

Only in Case A was a net comparison employed in the study as a whole. There were a number of factors at play here:

They did not create 'natural' counterparts to each other for net comparison because the benefits and costs were evaluated separately. As a result, the advantages or costs revealed were regarded as tools for accomplishing higher-level objectives. The evaluation's objectives were met with structural data on net value's influencing elements. The evaluation objectives did not yet necessitate a detailed budget.

All instances were approached from a means-toend perspective. To link multilevel goals and IT impacts in the business system, all situations used structural cause-and-effect analysis, and means-end valuing logic was a natural counterpart to that method. Cases where individual level analysis was not used (ERP and cloud development/test environments) did not use experience $\operatorname{logic}^{53}$.

\section{Samples for evaluation views}

A systemic glue for integrating various value conceptualizations was suggested by assessment views, first of all, in terms of structural and behavioral viewpoints. Second, qualitative-quantitative operationalizations of value encouraged an iterative and evolutionary approach. As a result, intangible and complicated IT impacts aren't excluded from value assessments because they're difficult to measure; rather, their inclusion drives gradual improvements in measures and quantification of soft values. Evaluating gives both qualitative and quantitative value information is also acceptable.

If you look at Case A from a structural perspective, you can see the effect chains (also known as value routes) that connect GMS to various gaming process areas, as well as how these process areas connect to the gaming business's earnings rationale. A time-dependent model was used to examine the behavior of a few structural components in greater detail. To illustrate the effects of GMS on manual workloads, qualitative causal-loop and stock-and-flow diagrams were used. In the qualitative work-load models, the system's value production processes were exposed, and value measures were pinpointed.. By including mathematical formulae and workload 
estimates into the models, we were able to gain a deeper qualitative insight. To quantify the potential value, we could run simulations that looked at the impact of time savings on the entire game content and on how much time was spent gaming in total. Moreover, the realised value of GMS was quantified by comparing present GMS-enabled gaming volume with hypothetical volumes where GMS automation was replaced by manual effort ${ }^{54,55}$.

Overall, the structural view was present in all situations since it constituted the foundation for comprehending value-affecting components and the interactions among them. It was present From the structural perspective, both qualitative and quantitative measures might be identified. Value creation techniques and value outcomes were reflected in the metrics. The value production method for both realized and potential value was explained using a behavioral approach. Static value elements were generally insignificant and only found in more complicated structures were those with dynamic value. Behaviour was developed either on a qualitative or a quantitative level by adding stock-and-flows to causal loop models.

\section{DESIGN GOALS}

General purpose IT assessment "Establishing the value or contribution produced by a certain IT investment" is the goal of IT evaluations (Andresen, 2001). For this, we use a Conceptual Framework that combines an analysis levels perspective to identify different stakeholder views on value - what is valuable and why; and a valuation logics perspective that introduces new ways of defining the meaning of value in relation to IT contributions. This helps us achieve our goal. This framework encourages us to look into the specific IT impacts of IT investments and make value judgments based on the comparison of these impacts to the multidimensional goals of a business system.

Purpose of the IT evaluation, process viewpoint. Considering IT evaluation as a set of actions that include comprehension, measurement, and assessment (Andresen, 2001). Conceptual Framework attempts to make complex value interpretations and dimensions easier to understand by grouping them together under three broad headings. They provide a conceptual framework for simplifying the identification and assessment of IT impacts in reality.. together. The Conceptual Framework promotes a goal-oriented approach to the actual evaluation process by being visually organized (when read from left to right). For all types of IT impacts to be evaluated, one must begin by gaining a thorough understanding of the business system with diverse stakeholders and their aims. While investigating the mechanisms that link IT impacts with value creation and determination, the process continues to change the evaluation efforts and methodologies to meet the requirements of IT decision- making ${ }^{56}$.

Measuring anything helps to make something clear. Conceptual Framework recognizes both qualitative and quantitative measurements and value analysis as a technique to interpret value information for various decision-making objectives and defines both value generation mechanisms and their outcomes as possible measurement targets. IT's primary goal and the decision-making process's primary goal. IT evaluation's specific purposes include determining whether or not IT is serving its intended purpose and providing useful information for decision-making. The IT department's priorities should be determined by the business system's objectives. conceptual framework encourages the identification of several levels of objectives and the connection between these objectives and the ultimate purpose of business systems. A structural valuation approach and an understanding of the means-end valuing logic help evaluate IT systems with vast and far-reaching implications, as well as aspects that complement them and networked goal hierarchies. When it comes to making decisions, the Conceptual Framework encourages you to consider both current and future IT investment. In reality, the assessment's temporal horizon isn't set in stone; possible and realized evaluation perspectives, taken combined, offer a lifecycle approach that takes into account the past, present, and future. Conceptual Framework indirectly encourages the progression of little decisions. Making links between decisions means that in the first phase, factors that affect value creation at the system structural level are identified and given the highest priority. Important decisions lead further efforts such as gathering hard/quantitative information regarding previously intangible/qualitative valueaffecting variables Quantitative value predictions based on net comparison valuing reasoning can be used to make the next round of judgments.

An all-encompassing strategy. Multiple levels of analysis are identified as part of the Conceptual Framework to support a holistic examination of the business system. When means-end valuing logic is identified, it fosters the search for causal linkages among various organizational goals. Systems thinking approaches like system dynamics can be used with the concepts offered in Conceptual Framework ${ }^{57}$. It is possible to combine qualitative/quantitative, structural/behavioral, and other approaches to system dynamics study without conflicting with one another. Analyzing IT impacts from structural, temporal, and behavioral perspectives is supported by the Conceptual Framework. Systemic understanding is built on the interplay of these different points of view. The concept of feedbacks, which is intimately linked to the causeand-effect analysis, is also critical for a systemic 
understanding. Conceptual Framework does not directly mention circular feedbacks or causal loops (only more general causal chains are indicated), but they should be taken into account in practical assessment methods that make use of Conceptual Framework. The causal-loop diagram (CLD) is a simple example of system dynamics in which feedbacks are essential. CLD is a crucial system dynamics technique ${ }^{58}$.

\section{CONSTRUCT VALIDITY}

The validity of the defined notions is evaluated in terms of how well they reflect the real phenomenon they are meant to address. Construction validity is a matter of degree, as is 'how well.' Section 4 and Appendices A and B give the findings of case samples illustrating the Conceptual Framework's constructs. Appendix $\mathrm{C}$ presents construct indicators that were used to map case samples to Conceptual Framework structures. Construct validity is established by the fact that we were able to develop relevant indicators for the constructs and that the indicators were able to classify case-specific instantiations. A few fascinating construct validity difficulties deserve to be discussed, on the other hand $^{59,60}$.

Because of this, it's important to keep experience-based valuing from being mixed up with the other two logics. It may be difficult to determine if an experience of the value of an IT influence is solely phenomenological or whether the value experience already contains an unconscious means-end or even net comparison judgments behind it $^{61}$. From three different views, the same value phenomenon may be observed here. However, from a practical standpoint, the fundamental aim of multiple valuing logics is to lead to conscious reasoning for value and to be able to connect the many reasonings, including tangible and intangible value parts, together ${ }^{62}$.

The fact that there are three levels of analysis creates another area of ambiguity. The valuing phenomenon can be studied from the perspective of an individual, but it is also observable at the level of a process $^{63}$. People use IT to complete certain parts of processes, and the varied implications are also obvious at an organizational level, as the process' output directly affects cash flow or the number of paying clients for a firm. For example, multilevel analysis allows you to observe how IT effects the entire company system by showing the phenomenon's nested nature. Regarding the evaluation view structures, we used qualitative-quantitative views in two senses, namely for characterizing the type of measurement/data and the type of overall systemic analysis used in the research $^{64}$. The description of qualitative systemic analysis is directly linked to the structural view of the system. To us, structural knowledge constitutes both a quantitative and qualitative evaluation of value because it identifies the value elements as well as their interactions within the system. Qualitative analysis, on the other hand, can look at system behavior, such as the direction in which values change and whether or not there are delays. This means that qualitative system analysis encompasses more than just a broad structural perspective $^{65-67}$.

\section{CONCLUSIONS}

In order to comprehend the systemic consequences of technology, people, and processes on the company's performance, an attempt is made to evaluate IT value. This understanding can be explicit, comparable, and time-horizon aware in numerous ways. For the purpose of evaluating IT value, we present a Conceptual Framework for bringing together and clarifying key constructs. Using a systemic approach, diverse valuation logics and meanings for value can be integrated together. A systemic perspective says that value is created as a result of the intricate interactions between the many parts of the business system. Each IT purpose and decision-making situation is considered when valuing. It supports this diverse environment by encouraging multilayer value analysis and by identifying multiple valuation logics and evaluation points of view that are part of the Conceptual Framework. To examine and synthesize value-based IT evaluation approaches, IS researchers might use Conceptual Framework. Using Conceptual Framework, practitioners can create shared understandings of complex value and different viewpoints on how to evaluate them using a common vocabulary. A systemic approach emphasizes the importance of integrating multiple points of view in order to arrive at a comprehensive understanding of what is important.

\section{REFERENCES}

1. Baak, S. (2008). The bilateral real exchange rates and trade between China and the U.S., China Economic Review, 19(2), 117-127.

2. Aziz, M.N., Horsewood, N. \& Sen, S. (2014). The first and second stage pass-through of exchange rates: A developing country perspective. Review of Development Economics, 18(3), 595-609.

3. Harvey, H., \& Hegerty, S.W. (2014). Industry trade and exchange-rate fluctuations: Evidence from the U.S. and Chile. International Review of Economics and Finance, 29, 619-626.

4. Adeyemi, O.A., \& Samuel, E. (2013). Exchange rate pass-through to consumer prices in Nigeria. European Scientific Journal, 9 (25), 110-123.

5. Joshi, V. and Little, I.M.D. (1994), "India: Macroeconomics and Political Economy, 19641991 ", Oxford University Press, New Delhi.

6. Kayhan Selim, Bayat Tayfur and Ugur Ahmet (2013), "Interest Rate and Exchange Rate 
Relationship in BRIC-T Countries", Ege Academic, Vol. 13 Issue 2

7. Kiyota, K., and Urata, S. (2004), "Exchange rate, exchange rate volatility and foreign direct investment", The World Economy, 27(10)

8. Linda S Goldberg (2006), "Exchange Rates and Foreign Direct Investment", Princeton Encyclopedia of the World Economy, Princeton University Press, New York.

9. Lorenzo Cappiello and Roberto A DeSantis (2005), "Explaining Exchange Rate Dynamics the Equity Return Parity Condition”, European Central Bank, Working Paper Series, No. 529 (September)

10. Marjan Petreski (2009), "Exchange-Rate Regime and Economic Growth: A Review of the Theoretical and Empirical Literature", Economics - The Open Access, Open Assessment E-journal, Discussion Paper No. 2009-31.

11. Michael Debabrata Patra and Sitikantha Pattanaik (1998), "Exchange Rate Management in India: An Empirical Evaluation”, Occasional papers / Reserve Bank of India, Vol. 19, 3.

12. Michael L Mussa (1984), "The Theory of Exchange Rate Determination”, National Bureau of Economic research, University of Chicago Press.

13. Cho, G., Sheldon, I.M., \& McCorriston, S. (2002). Exchange rate uncertainty and agricultural trade. American Journal of a grfcultural Economics, 84 ( 4), 931-942.

14. An, L., \& Wang, J. (2011). Exchange rate passthrough: Evidence based on vector autoregression with sign restrictions. Retrieved from https://www.dallasfed.org/assets/documents/institut el wpapers/2011/0070.pdf.

15. Aristotelous, K., \& Fountas, S. (2000). The impact of the exchange rate regime on exports: Evidence from bilateral exports in the European Monetary System. Journal of Economic Integration,15( 3), 506-526.

16. Brun-Aguerre, R., Fuertes A-M \& Phylaktis, K.(2012). Exchange rate pass-through into import prices revisited: What drives it? Journal of International Money and Finance, 31. 818-844.

17. Srinivasan $P$ and Kalaivani M, (2012), "Exchange Rate Volatility and Export Growth in India: An Empirical Investigation", MPRA Paper No. 43828.

18. Microfit", Palgrave Macmillan Limited, Hampshire.

19. D'Souza Errol (2008), "Macroeconomics", Pearson Education, New Delhi

20. Daniel S Shaffer (2010), "Profiting in Economic Storms", John Wiley and Sons, New Jersey.

21. Dutt Ruddar and KPM Sundharam (2010), "Indian Economy", S Chand and Co. Ltd, New Delhi.

22. Economic Survey (2013), Ministry of Finance, Government of India, New Delhi.

23. Fontanills George A and Tom Gentile (2002), "The Volatility Course”, Wiley Trading, Hoboken, US

24. Gujarathi Damodar $N$ (2009), "Basic Econometrics", Fifth Edition, McGraw-Hill Higher Education, New York

25. Gujarathi Damodar N (2011), “Econometrics by
Example”, Palgrave Macmillan Limited, Hampshire

26. Jalan Bimal (2001), "Banking and Finance in India: Managing New Challenges", in R Kapila and U Kapila (Ed.), India's Economy in the 21st Century, Academic Foundation, New Delhi.

27. Maddala GS (2001), "Introduction to Econometrics", Third Edition, John Wiley and Sons, Singapore.

28. Mills Terence C and Raphael N Markellos (2010), "Econometric Modelling of Financial Time Series", Third Edition Cambridge University Press, UK

29. Panneerelvam R (2011), "Research Methodology", PHI Learning Private Limited, New Delhi

30. Patterson Kerry (2002), "An Introduction to Applied Econometrics: A Time Series Approach”, Palgrave Macmillan Limited, Hampshire

31. Thirlwall AP (2006), "Growth and Development with Special Reference to Developing Economies", 8th edition, Palgrave Mc Milan, Hampshire

32. Srinivasan, T. N. (1998), "India's Export Performance A Comparative Analysis", Oxford University Press, New Delhi.

33. Takeshi Inoue and Shigeyuki Hamori (2009), "What Explains Real and Nominal Exchange Rate Fluctuations: Evidence from SVAR Analysis for India”, IDE Discussion Paper No. 216, Institute of Developing Economies, JETRO, October.

34. Chipili, J. M.( 2013). Exchange rate volatility and trade fiows in Zambia. African Development Review, 25(1), 55-66.

35. Gozgor, G. (2014). Aggregated and disaggregated import demand in China: An empirical study.Economic Modelling, $43,1-8$

36. Jiang, J., \& and Kim, D. (2013). Exchange rate pass-through to inflation in China. EconomicModelling , (33) 900-912.

37. Halka and Kotlowski. (2013). Does domestic output gap matter for inflation in a small open economy? Retrieved from http://www.nbp.pPpublikacje/materialy $i$ studia/152 en.pdf.

38. Jantarakolica, T., \& Chalermsook, P.(2012). Thai export under exchange rate volatility: A case study of textile and garment products. Procedia - Social and Behavioral Sciences, 40, 751 -755.

39. Bussiere, M., \& Peltonen, T. (2008). Exchange rate pass-through In the global economy: The role of emerging market economies, European Ceflfrai Bdnk working paper series No 951 .

40. Jimborean, R. (2013). The exchange rate passthrough in the new EU member states. Economic Sy'stems, 37(2), 302-329.

41. Pino, G. , Tas, D., \& Sharma, S. C. (2015). An investigation of the effects of exchange rate volatility on exports in East Asia.Retrived from http://www.tandfonline.com/dot/abs/10.1080/ 00036846.2015 .1122730 .

42. Kailiç, R. (2016). Regime-dependent exchange-rate pass-through to import prices. International Review of Economics and Finance, 41, 295-308.

43. Bhanumurthy, N. R., Das, S., \& 8ose, S. (2012). Oil 
price shock, pass-through policy and its impact on India. Working Paper No. 2012-99, National Institute of Public Finance and Policy, New Delhi. Retrieved from: http://www.nipfp.org.in/media/medialibrary/2013/0 4/wp_20l2_99.pdf.

44. Madesha, W., Chidoko, C., \& Zivanomoyo, J. (2013). Empirical Test of the relationship between exchange rate and inflation in Zimbabwe. Journal of Economics and Sustainable Development, 4(1), 52-58.

45. Choudhry, T. (2005) Exchange rate volatility and the United States exports: Evidence from Canada and Japan. Journal of the Japanese and International Economies, 19, 51-71.

46. Ozkan, 1., \&, Erden, L.(2015). Time-varying nature and macroeconomic determinants of exchange rate pass-through. International Review of Economics and Finance, 38, 56-66.

47. Peón, S.B.G., \& Brindis, M.A.R. (2014). Analyzing the exchange rate pass-through in Mexico: Evidence post inflation targeting implementation. Ensayos sobre Política Económica, 32 (74), 18- 35.

48. Pesaran, M. H., Shin, Y., \& Smith, R. J. (2001). Bounds testing approaches to the analysis of level relationships. Journal ofApplied Econometrica, 16(3), 289-326.

49. Yanamandra, V. (2015). Exchange rate changes and inflation in India: What is the extent of exchange rate pass-through to imports? Economic Analysis and Policy, 47, 57-68.

50. Prasertnukul, W., Kim, D., \& Kakinaka, M. (2010). Exchange rates, price levels, and inflation targeting: Evidence from Asian Countries, Japan and the World Economy, 22, 173-182.

51. Rajwade, A. V. (2016) Can We Afford Build-up of External Liabilities? Economic and Political Weekly, 51 (29), 72-75.

52. Seerattan, D., \& Spagnolo, N. (2009). Central bank intervention and foreign exchangemarkets. Applied Financial Economics, 19(17), 1417-1432.

53. Slovic, P. (1986). Psychological study of human judgment: implications for investment decision making.

54. Wang, P. (2009). The economics of foreign exchange and global finance. Springer Science \& Business Media.

55. Saha, S., \& Zhang Z. (2013). Do exchange rates affect consumer prices? A comparative analysis for Australia, China and India. Mathematics and Computers in Simulation, (93) 128-138.

56. Sebastian, A., Sharma,U., Sonna, T., \& Joshi, H. (2014). Impact of real exchange rate volatility on use-based industrial production in India, RBI working paper series, W P S (DEPR): 05 / 2014, Department of Economic and Policy Research, The Reserve Bank of India.

57. Shahbaz, M, Awan, R,U, \& Ahmad, K 2011, 'The exchange value of the Pakistan rupee \& Pakistan trade balance: an ARDL bounds testing approach', The Journal of Developing Areas, 44,69-93.

58. Wang,C-H., Lin, C-H., A, Yang, C-H. (2012). Short- run and long-run effects of exchange rate change on trade balance: Evidence from China and its trading partners. Japan and the World Economy, 24, 266-273.

59. Srinivasan, P., \& Kalaivani, M. (2012). Exchange rate volatility and export growth in India: An empirical investigation.Retrieved from http://mpra.ub.uni-muenchen.de/43828/.

60. Takhtamanova, Y. F. (2010). Understanding changes in exchange rate pass-through. Journal of Macroeconomics, 32, 1118-1130.

61. Brissimis, S. N., \& Chionis, D. P. (2004). Foreign Exchange Market Intervention:

62. Implications of Publicly Announced and Secret Intervention for the Euro Exchange Rate and Its Volatility. Journal of Policy Modeling, 26, 661-673.

63. Canova, F. (1993). Modelling and forecasting exchange rates with a Bayesian time varying coefficient model. Journal of Economic Dynamics and Control, 17(1), 233-261.)

64. Thorbecke, W. (2008). The effect of exchange rate volatility on fragmentation in East Asia: Evidence from the electronics industry, Journal of the Japanese and International Economies, 22, 535544.

65. Dua, P., \& Ranjan, R. (2011). Modelling and Forecasting the Indian RE/US Dollar Exchange Rate (No. 197).

66. Egert, B., \& Lang, M. (2006). Foreign Exchange Intervention In A Small Emergingb Market: The Case Of Croatia. Economic Change and Restructuring, 39, 35-62.

67. Wilson, P., \& Tat., K.C. (2001). Exchange rates and the trade balance: The Case of Singapore 19701996. Journal of Asian Economics, 12 (1), 47-63. 